\title{
(C) OPEN ACCESS \\ Trends in adolescent mental health during economic upturns and downturns: a multilevel analysis of Swedish data 1988-2008
}

\author{
Yunhwan Kim, Curt Hagquist
}

\begin{abstract}
Centre for research on child and adolescent mental health, Karlstad University, Karlstad Sweden
\end{abstract}

\section{Correspondence to} Dr Yunhwan Kim, Centre for research on child and adolescent mental health, Karlstad University, Karlstad 65188, Sweden; yunhwan.kim@ kau.se

Received 27 July 2017 Revised 20 October 2017 Accepted 15 November 2017 Published Online First 4 December 2017

\section{ABS}

\section{ABSTRACT}

Background A long-term trend of increasing mental health problems among adolescents in many Western countries indicates a great need to investigate if and how societal changes have contributed to the reported increase. Using seven waves of repeated cross-sectional data collected between 1988 and 2008 in Sweden, the current study examined if economic factors at the societal level (municipality unemployment rate) and at the individual level (worry about family finances), and their interaction could explain a secular trend in mental health problems.

Methods Participants were 17533 students of age $15-16$ years $(49.3 \%$ girls), from 14 municipalities in a county of Sweden. Data on adolescents' mental health (psychosomatic problems) and worry about family finances were obtained using a self-report questionnaire. A series of multilevel regression analyses were conducted in order to explain the trends in adolescents' mental health.

Results The results indicated that the individual-level predictor (worry about family finances) significantly explained the increasing rates of adolescents' psychosomatic problems. This was particularly the case during the mid-1990s, which was characterised by a severe recession in Sweden with high unemployment rates. For example, after accounting for adolescents worry, a significant increase in psychosomatic symptoms between 1988 and 1998 among girls $(b=0.112, P<0.05)$ disappeared $(b=0.018, P>0.05)$ and a non-significant decrease between 1988 and 1995 among boys $(b=-0.017, P>0.05)$ became significant $(b=-0.142$, $\mathrm{P}<0.05)$. Neither municipality unemployment rate nor its interaction with adolescents' worry explained psychosomatic problems.

Conclusions The findings demonstrate the effects of adolescents' worry about family finances on a secular trend in mental health problems during an economically bleak period of time. The study highlights the need for repeated measurements including a large number of time points over a long time period in order to analyse time-specific putative explanatory factors for trends in adolescent mental health problems.

\section{INTRODUCTION}

CrossMark

To cite: Kim Y, Hagquist C. J Epidemiol Community Health 2018:72:101-108.
Mental health problems during adolescence accompany numerous concurrent and long-term negative consequences in terms of, for example, functional impairments, educational and relational achievements, and career development. ${ }^{1-4}$ Accordingly, it is a pressing concern that about $10 \%$ to $20 \%$ of adolescents today suffer from mental health problems. ${ }^{5}$ Epidemiological studies have reported that adolescents' mental health problems today are worse than those a few decades ago. ${ }^{5}$ Understanding of what contributed to the long-term increase in adolescent mental health problems is important in order to improve their mental health. ${ }^{78}$ While some societal changes during the past few decades have been suggested as contributing to the worsening trend, explanatory trend analyses that enable substantiation of such hypotheses are scarce in the literature. $^{9} 10$

The current study investigated if societal changes in the economic sector would explain the trend of increasing mental health problems among Swedish adolescents from 1988 to 2008. A reported longterm increase in mental health problems among Swedish adolescents ${ }^{11}$ and changes in the economic situation in Sweden during the investigation period provided a unique opportunity to examine the potential effects of economic factors on the trend in mental health problems. Specifically, the current study examined if economic factors at the societal level (ie, unemployment rate) and at the individual level (ie, worry about family finance), and their interaction explained the trend in mental health problems among Swedish adolescents.

\section{Unemployment rate}

Various theoretical perspectives and empirical studies suggest that unemployment has detrimental impacts on individuals' mental health. ${ }^{12}$ Although the majority of studies concerns adults, several empirical studies focus on the consequences of youth unemployment for mental health ${ }^{13-16}$ as well as the increased risks of mental health problems among children with unemployed parents. ${ }^{1718}$ Our research question was if, or to what extent, increasing unemployment explained trends in adolescent mental health. One of the most comprehensive studies on this subject concluded that unemployment does not seem to have contributed to the historical deterioration of mental health since the period of worsening adolescent mental health problems is characterised by economic prosperity. ${ }^{19}$ An empirical study by Buffel et $a l^{20}$ reported that, among adults in 27 European countries, levels of mental health problems were not higher during periods of high unemployment rates than during periods of low unemployment rates. Another empirical study among adolescents in 10 European countries found a significant association over 
time between the proportion of youth not in the labour force and adolescent mental health problems. ${ }^{21}$ In sum, the previous studies imply that societal unemployment rate may not be a critical factor associated with the trend in adolescent mental health problems. The number of studies in this field is still highly limited, and no study has examined interactions between societal-level unemployment rate and potentially related individual-level factors.

\section{Worry about family finances}

A leading scholar in the field of adolescent mental health trends, Collishaw, ${ }^{5}$ stated in his recent review that 'most studies to date have focused on broad-based sociodemographic risk markers (eg, social class, family type), rather than on proximal mechanisms (eg, quality of parent-child relationships) (pp. 386)'. Based on that comment, we included an indicator in our study that is more closely related to adolescents' psychological processes: their worry about family finances. The associations between adolescents' worries and their mental health problems are well established in individual-level studies. Worry is a common phenomenon throughout childhood and adolescence, and, more importantly, is related to mental health problems. ${ }^{22}$ Among adolescents, worries are found to relate to anxiety and depression both cross-sectionally and longitudinally. ${ }^{23}$ Specifically concerning worry about family finances and psychosomatic symptoms, Hagquist ${ }^{24}$ showed, in a cross-sectional study which was partly based on the same data as was used in the current study, that adolescents who worried more about family finances were seven times more likely to report mental health problems.

Despite the well-established relation between worry and mental health among adolescents as described above, only two studies, both conducted in Scotland, have examined the effects of adolescents' worries on trends in mental health problems. ${ }^{25} 26$ These studies found that adolescents' worries explained trends in mental health problems, and that the magnitudes of such effects were different according to the types of worry. Given the type-specific effects of worry observed in those studies, there is a need for empirical studies that uncover the specific effects of different types of worry on adolescent mental health trends. To date, no study is available in the literature that has explored whether worry about family finances may explain trends in mental health problems among adolescents.

\section{Multiple time points in studies on time trends}

It has been acknowledged in the trend analysis literature that appropriately capturing a secular trend requires data collected over a sufficiently long time period, or at least 7 years. ${ }^{27}$ Another consideration, which has received less attention, concerns the interval between the two ends of a continuum. The majority of explanatory trend analyses to date have examined only two time points over a time period of 10 or more years. This prevents capturing potential fluctuations in the effects of putative explanatory factors on time trends. Given the awareness in the literature that changes in explanatory factors and their impacts on adolescents' mental health can occur in even a short period of time, ${ }^{8}$ in the current study we used data from seven assessments collected over a period of 20 years.

\section{The current study}

Using comprehensive regional data from Sweden that enabled multilevel analyses, the current study aimed to explain a secular trend in adolescents' mental health problems from 1988 to 2008 in light of profound societal changes in economic conditions.
Specifically, we examined the impact of a societal-level factor (municipality unemployment rate), an individual-level factor (worry about family finances) and the interaction between the two on adolescents' psychosomatic problems.

\section{METHOD \\ Participants}

The sample used in the current study was composed of 17533 students (aged 15-16, 49.3\% girls). This analytic sample was derived from the Young in Värmland study in which data have been collected every 3 to 4 years from all students in the last year of compulsory school in the 16 municipalities of the county of Värmland, Sweden. The sample was derived from the adolescents who participated between 1988 and 2008 (comprising 7 years of investigations). Across all years of investigation, of the eligible 23247 individuals, 20591 participated (the yearly participation rate was $88.6 \%$ on average). Among them, 3058 were excluded due to two municipalities not participating in all 7 years of investigations, $(n=2678)$ or since they did not provide information on gender or worry $(n=380)$.

\section{Procedure}

For each assessment, data collection took place in the second (spring) semester of the ninth school year. School personnel distributed a self-report questionnaire to the students in their classrooms during regular school hours. Participation was voluntary. Students completed the questionnaire anonymously and returned it to school personnel in a sealed envelope. The data collection procedure followed the research ethics principles in humanistic-social science research stipulated by the Swedish Research Council. The questionnaire and the principles guiding the data collections in 2005 and 2008 were reviewed by the Ethics Committee of Karlstad University, Sweden.

\section{Measure}

\section{Psychosomatic problems}

Psychosomatic problems were measured using the PsychoSomatic Problems (PSP) scale which has previously been examined and shown to be reliable and to work invariantly across the years of investigations. ${ }^{28}$ The PSP scale is constructed through a summation of the adolescents' responses (raw scores) on eight items about experiences during the school year of any problems, described in each item (difficulty in concentrating, problems in sleeping, headaches, stomachaches, feeling tense, poor appetite, feeling sad and feeling giddy/dizzy). There were five response categories: never, seldom, sometimes, often and always. Based on a psychometric analysis with the Rasch model, a few items were resolved for differential item functioning across genders. ${ }^{28}{ }^{29}$ Using the Rasch model, the non-linear raw scores were transformed to a linear scale on which each person has a location (logit) value. Lower values on the logit scale indicate a lower degree of psychosomatic problems.

\section{Unemployment rate}

Unemployment rates for each municipality for each year of investigation were obtained from Statistics Sweden. The unemployment rate shows the proportion of unemployed persons out of the total number of persons in the labour force aged between 16 and 64 years. Unemployed persons consist of those who are not employed but are seeking employment and are ready to start a job if acquired as well as those who are currently participating in employment support programmes. Among those who do not have a job, students, pensioners and full-time homemakers and 


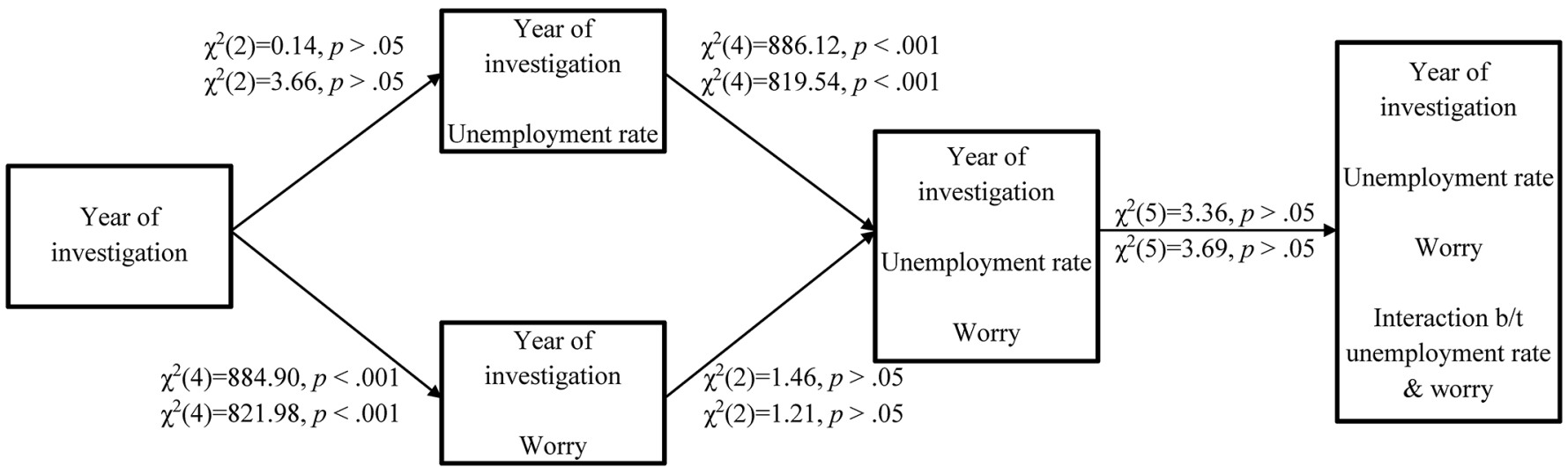

Figure 1 Likelihood ratio test (LRT) flow chart and results. Each rectangular box indicates the independent variable(s) in the model. The LRT results above refer to girls, and below, boys.

those with a long-term illness are not considered to be unemployed but to be outside the labour force. The unemployment rate of any particular year concerns the unemployment rate from the beginning to the end of the year. Therefore, we used the unemployment rate at the year before the year of investigation, in order to ensure that the unemployment rate was not affected by events occurring after the data collections took place.

\section{Worry about family finances}

Participants were asked if they had recently experienced worry about family finances. On this question, there were five response options: never, seldom, sometimes, often and always.

\section{Analysis}

A series of multilevel analyses was conducted with individuals at level 1 , nested in years of investigation at level 2, nested in municipalities at level 3. Gender differences in the levels and/ or patterns of secular trend in adolescent mental health are reported in the literature in general ${ }^{56}$ as well as in a previous study based on Young in Värmland data. ${ }^{11}$ Therefore, all analyses were conducted separately for girls and boys.

In order to determine what significantly explains adolescents' mental health problems, we examined several multilevel models, starting with a simple model and expanding it to more complex models as illustrated in figure 1. Usually, the simplest model does not include any independent variable. However, in this study the simplest model included year of investigation because that variable served as reference point to measure the effects of the variables of our interest. At each step, we compared a simpler model with a more complex model using likelihood ratio tests (LRT). The most parsimonious model was chosen when the inclusion of an additional variable did not significantly improve the model fit.

\section{RESULTS}

\section{Descriptive results}

First, unemployment rate is presented in figure 2 which consists of three subfigures. Figure $2 \mathrm{~A}$ presents the raw data of unemployment rate of each municipality at each year of investigation, which reflects the combination of both cross-sectional (between municipalities) and longitudinal (over time) variations in unemployment rates. Following Fairbrother's ${ }^{30}$ suggestion, these two sources of variation were separated into cross-sectional (figure 2B) and longitudinal unemployment rates (figure 2C), which were separately entered in all analyses. The raw data in figure 2A show that the mid-1990s is characterised by economic downturns with higher unemployment rates than at other time points. After adjusting for differences between municipalities, this pattern is further streamlined in figure $2 \mathrm{C}$, more clearly indicating the highest economic downturns during the mid-1990s across all municipalities. Second, the mean levels of adolescents' worry about family finances according to each year of investigation are presented in figure 2D. Girls worried about family finances more than boys at all years of investigations. More importantly, both girls and boys reported relatively higher levels of worries during the mid-1990s, which coincides with the economic downturns reported above.

Third, the secular trends in adolescents' psychosomatic problems are reported under model 2 in table 1 and illustrated in figure 3. Among girls, the level of psychosomatic problems continued to increase until 2005 and decreased slightly in 2008. In comparison to the level of psychosomatic problems in 1988, the levels in 1998 and thereafter were significantly higher. The pattern was different among boys. The levels of psychosomatic problems decreased before starting to increase from 1991, which lasted until 2005. Similar to the pattern for girls, a slight decrease in 2008 was observed. However, it was only from 1998 and thereafter that the levels of psychosomatic problems were higher than those in 1988 , although this was not statistically significant.

\section{Explanation of psychosomatic problems}

Note that years of investigation were entered as dummy variables first (model 2 in table 1). The regression coefficient for each year of investigation represents the difference in the level of psychosomatic symptoms between the corresponding year and the reference year of 1988. It also serves, in case any putative risk factor significantly explains adolescents' mental health, as a reference point to examine how much the risk factor influenced a secular trend in adolescent mental health problems.

The main analyses started by investigating which variable(s) significantly contributed to improved model fit based on the LRT results. As shown in figure 1, the only case where a more complex model fit significantly better than a less complex model was when adolescents' worry about family finances was included in the more complex model. Neither unemployment rate alone nor its interaction with adolescents' worry significantly improved model fit. That is, overall, adolescents living in times with a higher unemployment rate did not report higher levels of psychosomatic symptoms than adolescents living in times with lower unemployment rates. Also, the effect of adolescents' 

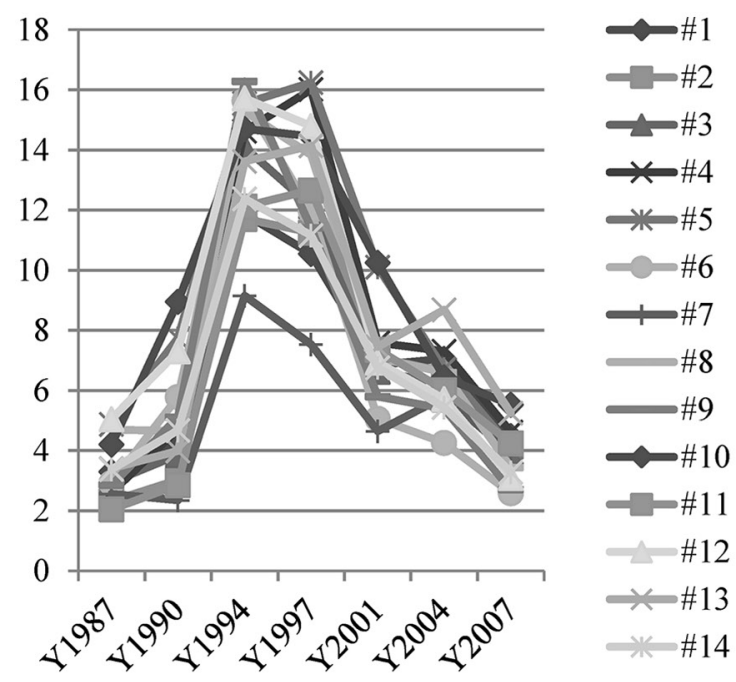

A Unemployment rate of each municipality at each assessment time
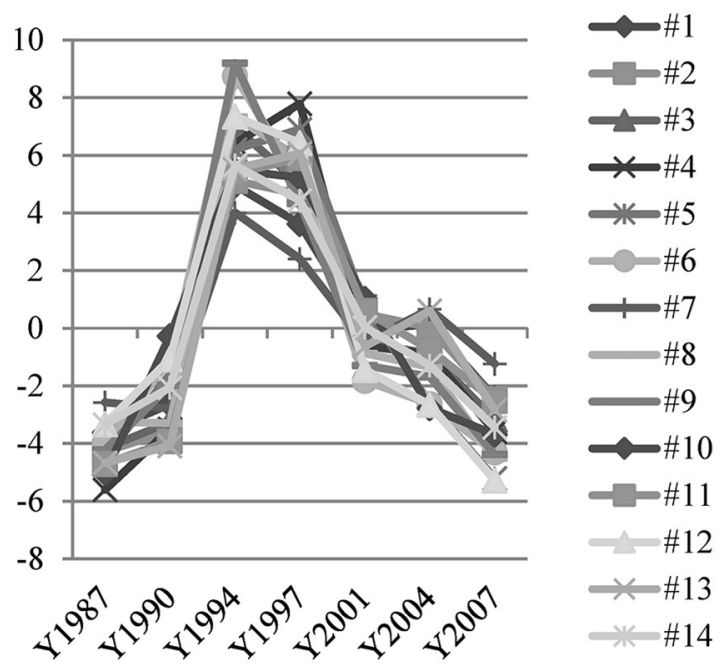

\section{Demeaned unemployment rate}

(obtained by subtracting $2 \mathrm{~b}$ from $2 \mathrm{a}$ )

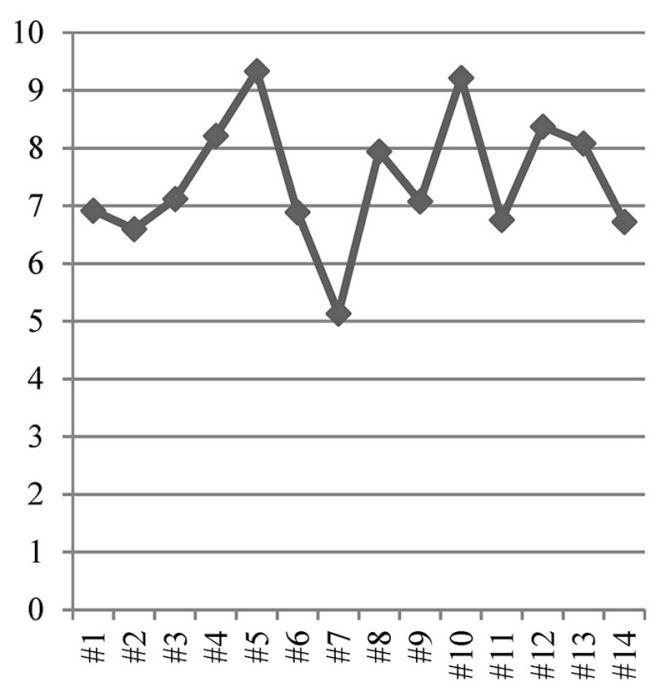

B Unemployment rate of each municipality

averaged across all assessment times

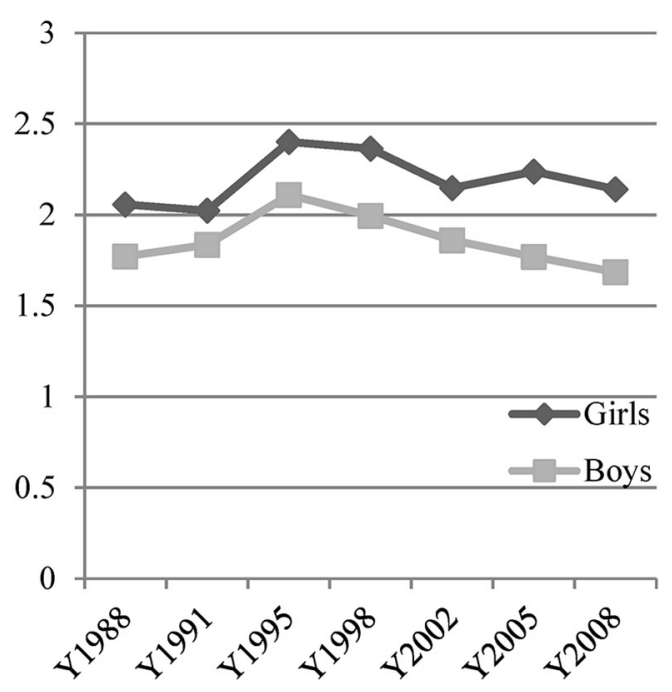

D Worry about family finances

Figure 2 Unemployment rate and adolescents' worry about family finances. Municipality numbers indicate \#1.Karlstad \#2.Kil \#3.Forshaga \#4.Storfors \#5.Hagfors \#6.Eda \#7.Hammarö \#8.Sunne \#9.Årjäng \#10.Munkfors \#11.Grums \#12.Torsby \#13.Filipstad and \#14.Arvika.

worry on mental health problems did not differ according to unemployment rate at the municipality level across the years of investigation. Therefore, we only included year and worry in our final model.

The final model (model 3 in table 1) reveals that students who reported higher levels of worry about family finances reported higher levels of psychosomatic symptoms. This was the case for both girls (regression coefficients ranging from 0.275 to 1.088 , $\mathrm{P}<0.001$ ) and boys (regression coefficients ranging from 0.367 to $1.494, \mathrm{P}<0.001)$.

The regression coefficients for years of investigation in model 3 in table 1 represent the difference in psychosomatic symptoms between the corresponding year and the reference year after accounting for the effects of worry about family finances. To facilitate comparisons, the regression coefficients for years of investigations before and after including worry about family finances are illustrated in figure 3. The results indicate that, in most cases, adolescents' mental health would have been more favourable in the absence of adolescents' worry about family finances. In particular, consistent with the heightened levels of adolescents' worry during the mid-1990s, the differences in psychosomatic problems before and after adjustment for the effect of adolescents' worry were especially pertinent during the mid-1990s. Consequently, among girls, the marginally significant 


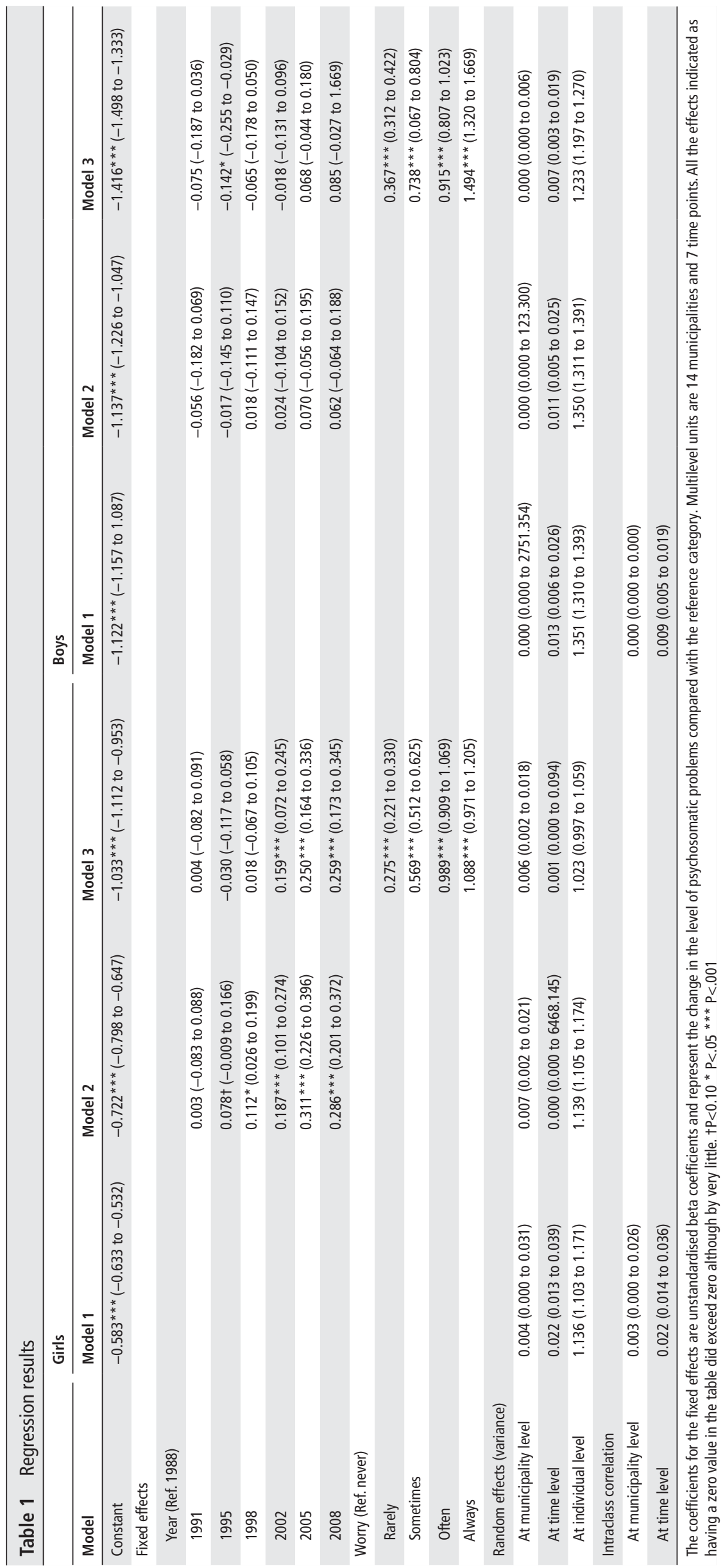




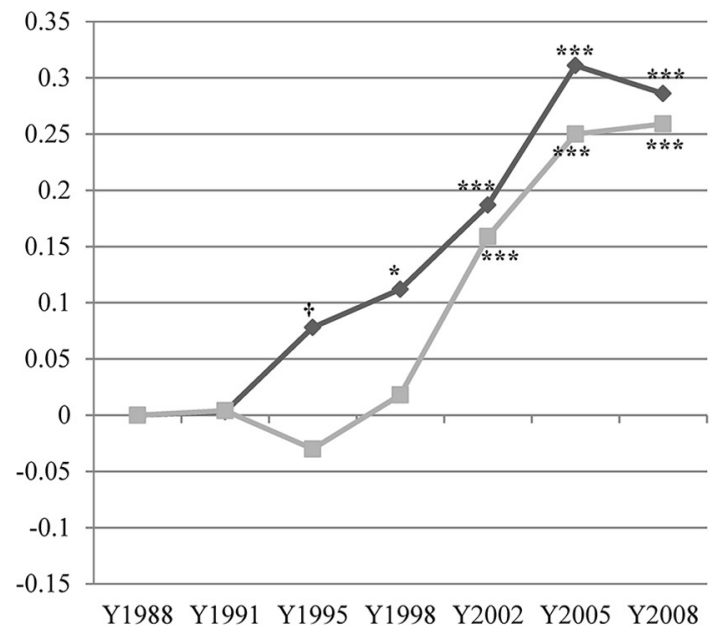

A Girls

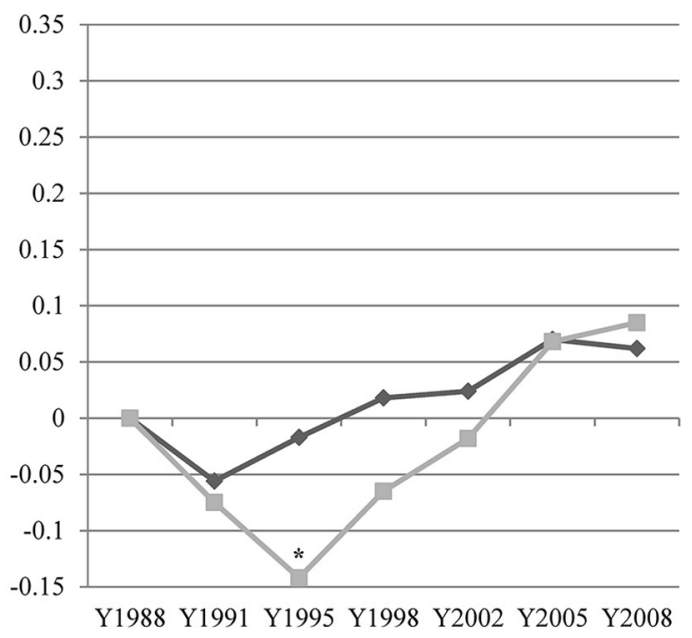

B Boys

Figure 3 Psychosomatic problems according to years of investigation. The upper line indicates unstandardised regression coefficients prior to adjusting for the effects of worry (model 2 in table 1). The lower line indicates unstandardised regression coefficients after adjusting for the effects of worry (model 3 in table 1). Note that statistical significance refers to the difference between the reference year (1988) and the selected year, not the difference between before and after adjustment for worry about family finances in the corresponding year. $+P<0.10{ }^{*} P<0.05{ }^{* * *} P<0.001$.

difference in psychosomatic problems between 1988 and 1995 $(\mathrm{b}=0.078, \mathrm{P}=0.08)$ and the significant difference between 1988 and $1998(\mathrm{~b}=0.112, \mathrm{P}<0.05)$ disappeared after accounting for the effects of worry $(b=-0.030$, n.s. and $b=0.018$, n.s., respectively). Among boys, initially, the differences for those years were not significant. However, after adjusting the effects of worry, the initially non-significant difference between 1988 and 1995 $(b=-0.017$, n.s.) became significant $(b=-0.142, P<0.05)$, indicating that boys' mental health would have been significantly more favourable in 1995 than in 1988, in the absence of worry about family finances.

\section{DISCUSSION}

This study examined the effects of economic factors, both at the societal level (municipality unemployment rate) and the individual level (worry about family finances), and the interaction between them on the secular trends in Swedish adolescents' psychosomatic problems based on cross-sectional data collected seven times between 1988 and 2008. We found that adolescents' worry about family finances was strongly associated with adolescents' psychosomatic problems. Moreover, worry about family finances had a detrimental impact on the trend of mental health problems especially during the mid-1990s, a time when Swedish society was characterised by an economic downturn with high unemployment rates.

\section{Unemployment rate and adolescents' mental health}

In the current study, unemployment rate at the societal level did not directly explain the increasing trend in adolescents' mental health problems. This finding is consistent with previous studies that also failed to detect a direct effect of the societal unemployment rate on deteriorating mental health trends. ${ }^{19-21}$ The current study adds to the existing literature by showing that societal-level unemployment rate also did not explain the trend in adolescents' mental health through an interaction with individual-level worry.

\section{Adolescents' worry and mental health}

Adolescents' worry about family finances was significantly associated with adolescents' mental health problems. Consistent with the previous studies, ${ }^{22-24}$ the more the adolescents worried, the higher their psychosomatic problems were. More importantly, our study complements previous studies that reported effects of worry about school, family relationships and own performance on the trend in adolescent mental health problems. ${ }^{25} 26$ We demonstrated that worry about family finances may also explain the trend in mental health problems among adolescents. Specifically, the reported detrimental effects on adolescent mental health were particularly salient during the time of economic downturns in the mid-1990s in Sweden when adolescents' worry about family finances also reached its peak level. During that time period, in parallel to increasing unemployment rate, there were also deteriorations of the Swedish welfare system. ${ }^{31}$ Indeed, the inflated adjusted household income among families with children was estimated to decrease during this time period, ${ }^{32}$ which also may have served as a contributor to adolescents' worry about family finances. The current study is the first to examine the specific relation between worry about family finances and mental health problems among adolescents across a long time period using repeated cross-sectional multilevel data that were collected at a large number of time points.

Our findings indicate that a single factor is not sufficient to understand the entire long-term trend of mental health problems. In the current study, most of the increase in mental health problems in the mid-1990s disappeared after accounting for the effects of adolescents' worries; however, no similar effects were found at later time points. This is consistent with some literature that attributed the increase in mental health problems mostly to non-economic factors such as those related to education, family and self-image/identity. ${ }^{9}{ }^{1025}$ Therefore, the current study highlights a critical need for future studies to investigate multiple explanatory factors using multiple time points. Such studies have the potential to uncover which specific factors at which time points may be responsible for the increased trend in adolescent mental health problems. 
Another implication of our findings pertains to an effective strategy to counteract, or prevent, the negative effects of economic downturns on mental health. Reflecting on the potential effectiveness of strategies that target societal risk markers and its underlying mechanisms, Collishaw et $a l^{33}$ concluded that 'Policy initiatives are likely to be most beneficial when they effect changes in these underlying risk mechanisms (pp. 2584).' We highlight that our findings support such a view.

\section{Limitations}

It should be clearly noted that the failure to detect any effect of unemployment rate at the societal level may be due to the small variation in psychosomatic problems at higher levels in our multilevel models as indicated by small intraclass correlations in table 1. Moreover, the findings from our repeated cross-sectional design do not allow for causal inferences. We therefore cannot rule out the possibility of bidirectional effects between adolescents' worry and psychosomatic symptoms. In addition, while the current study took advantage of a highly reliable outcome measure for psychosomatic problems, the reliability of the explanatory variable is limited because adolescents' worry about family finances is measured by a single item. Lastly, it should be noted for appropriate generalisation of the current findings that the unemployment rate used in the current study refers more to a general economic social milieu rather than to the specific economic security of a certain target group.

\section{CONCLUSION}

The current study demonstrated the negative effects of economic factors on the secular trend in adolescents' mental health problems. Adolescents' worry about family finances was related to higher levels of psychosomatic problems. In addition, such detrimental effects were salient during economic downturns, explaining the worsened mental health problems during economically challenging time periods. While adolescents' individual-level worry may be considered as a meaningful factor

\section{What is already known on this subject}

- Adolescents' mental health problems have been characterised by a long-term increasing trend in many developed Western countries.

- Unemployment and worry about family finances explain mental health problems among adolescents.

\section{What this study adds}

- The current study adds that adolescents' worry about family finances explained the trend in adolescents' mental health problems and that its detrimental effect was salient particularly when society was hit by an economic recession. This indicates a need to pay a careful attention to timespecific effects of putative risk factors in analyses of trends in adolescent mental health problems.

- In light of the findings in the current study, we call for attention to adolescents' worry about family finances in preventive and health promotion work in particular during economically challenging times. in explaining the trend in their mental health problems during downturns in the economy, it is premature to make any firm conclusions about the potential effects of broader societal-level factors.

Contributors YK and $\mathrm{CH}$ conceptualised the study together. YK wrote the first draft and conducted the main analyses while $\mathrm{CH}$ conducted the psychometric analysis for the measurement and revised the draft. The draft was then circulated several times between the two authors until they agreed on the final manuscript.

Funding This work was supported by Forte: the Swedish Research Council for Health, Working Life and Welfare (Grant number: 2012-1736).

Competing interests None declared.

Provenance and peer review Not commissioned; externally peer reviewed.

Open Access This is an Open Access article distributed in accordance with the Creative Commons Attribution Non Commercial (CC BY-NC 4.0) license, which permits others to distribute, remix, adapt, build upon this work non-commercially, and license their derivative works on different terms, provided the original work is properly cited and the use is non-commercial. See: http://creativecommons.org/ licenses/by-nc/4.0/

(C) Article author(s) (or their employer(s) unless otherwise stated in the text of the article) 2018. All rights reserved. No commercial use is permitted unless otherwise expressly granted.

\section{REFERENCES}

1 van Geelen SM, Hagquist C. Are the time trends in adolescent psychosomatic problems related to functional impairment in daily life? a 23-year study among 20,000 15-16year olds in Sweden. J Psychosom Res 2016;87:50-6.

2 Mojtabai R, Stuart EA, Hwang I, et al. Long-term effects of mental disorders on marital outcomes in the national comorbidity survey ten-year follow-up. Soc Psychiatry Psychiatr Epidemiol 2017;52:1217-26.

3 Mojtabai R, Stuart EA, Hwang I, et al. Long-term effects of mental disorders on educational attainment in the National Comorbidity Survey ten-year follow-up. Soc Psychiatry Psychiatr Epidemiol 2015;50:1577-91.

4 Mojtabai R, Stuart EA, Hwang I, et al. Long-term effects of mental disorders on employment in the National Comorbidity Survey ten-year follow-up. Soc Psychiatry Psychiatr Epidemiol 2015;50:1657-68.

5 Collishaw S. Annual research review: Secular trends in child and adolescent mental health. J Child Psychol Psychiatry 2015;56:370-93.

6 Bor W, Dean AJ, Najman J, et al. Are child and adolescent mental health problems increasing in the 21 st century? A systematic review. Aust N Z J Psychiatry 2014:48:606-16.

7 Collishaw S, Maughan B, Natarajan L, et al. Trends in adolescent emotional problems in England: a comparison of two national cohorts twenty years apart. J Child Psychol Psychiatry 2010;51:885-94.

8 Maughan B, Collishaw S, Meltzer $\mathrm{H}$, et al. Recent trends in UK child and adolescent mental health. Soc Psychiatry Psychiatr Epidemiol 2008;43:305-10.

9 Schepman K, Collishaw S, Gardner F, et al. Do changes in parent mental health explain trends in youth emotional problems? Soc Sci Med 2011;73:293-300.

10 von Soest T, Wichstrøm L. Secular trends in depressive symptoms among Norwegian adolescents from 1992 to 2010. J Abnorm Child Psychol 2014;42:403-15.

11 Hagquist C. Psychosomatic health problems among adolescents in Sweden-are the time trends gender related? Eur J Public Health 2009;19:331-6.

12 Paul Kl, Moser K. Unemployment impairs mental health: meta-analyses. J Vocat Behav 2009;74:264-82

13 Strandh M, Winefield A, Nilsson K, et al. Unemployment and mental health scarring during the life course. Eur J Public Health 2014;24:440-5.

14 Hagquist C, Starrin B. Youth unemployment and mental health-gender differences and economic stress. Int J Soc Welf 1996;5:215-28.

15 Brydsten A, Hammarström A, Strandh M, et al. Youth unemployment and functional somatic symptoms in adulthood: results from the Northern Swedish cohort. Eur J Public Health 2015:25:796-800.

16 Winefield $\mathrm{AH}$. To the psychological effects of youth unemployment: international perspectives. J Adolesc 1997;20:237-41.

17 Shanahan L, Copeland W, Costello EJ, et al. Specificity of putative psychosocial risk factors for psychiatric disorders in children and adolescents. J Child Psychol Psychiatry 2008:49:34-42.

18 Frasquilho D, de Matos MG, Marques A, et al. Factors affecting the well-being of adolescents living with unemployed parents in times of economic recession: findings from the Portuguese HBSC study. Public Health 2017;143:17-24.

19 Rutter M, Smith DJ. Psychosocial disorders in young people: time trends and their causes. Chichester, UK: Wiley, 1995. 
20 Buffel V, van de Straat V, Bracke P. Employment status and mental health care use in times of economic contraction: a repeated cross-sectional study in Europe, using a three-level model. Int J Equity Health 2015;14:29.

21 Lager AC, Bremberg SG. Association between labour market trends and trends in young people's mental health in ten European countries 1983-2005. BMC Public Health 2009;9:325.

22 Muris P, Meesters C, Merckelbach H, et al. Worry in normal children. J Am Acad Child Adolesc Psychiatry 1998;37:703-10.

23 Young CC, Dietrich MS. Stressful life events, worry, and rumination predict depressive and anxiety symptoms in young adolescents. J Child Adolesc Psychiatr Nurs 2015;28:35-42.

24 Hagquist CE. Economic stress and perceived health among adolescents in Sweden. $J$ Adolesc Health 1998;22:250-7.

25 Sweeting $H$, West $P$, Young $R$, et al. Can we explain increases in young people's psychological distress over time? Soc Sci Med 2010;71:1819-30.

26 West P, Sweeting H. Fifteen, female and stressed: changing patterns of psychological distress over time. J Child Psychol Psychiatry 2003;44:399-411.
27 Eimecke S, Pauschardt J, Remschmidt $\mathrm{H}$, et al. Time trends in psychopathology. Z Kinder Jugendpsychiatr Psychother 2011;39:187-95.

28 Hagquist C. Psychometric properties of the psychosomatic problems scale: a rasch analysis on adolescent data. Soc Indic Res 2008;86:511-23.

29 Hagquist C. Evaluating composite health measures using rasch modelling: an illustrative example. Soz Praventivmed 2001:46:369-78.

30 Fairbrother M. Two multilevel modeling techniques for analyzing comparative longitudinal survey datasets. Political Science Research and Methods 2014;2:119-40.

31 Marklund U. Skolbarns halsovanor under ett decennium. tabellrapport. health behavior in school-aged children. a WHO collaborative study. Stockholm: Folkhälsoinstitutet, 1997.

32 Socialdepartementet. Ensamföräldrarna - en utsatt grupp. välfärdsprojektets skriftserie fakta/kunskap. Stockholm: Socialdepartementet, 1996.

33 Collishaw S, Goodman R, Pickles A, et al. Modelling the contribution of changes in family life to time trends in adolescent conduct problems. Soc Sci Med 2007;65:2576-87. 